\title{
Response of the Greenland and Antarctic Ice Sheets to Multi-Millennial Greenhouse Warming in the Earth System Model of Intermediate Complexity LOVECLIM
}

\author{
P. Huybrechts $\cdot$ H. Goelzer $\cdot$ I. Janssens $\cdot$ E. Driesschaert • \\ T. Fichefet $\cdot$ H. Goosse $\cdot$ M.-F. Loutre
}

Received: 1 February 2011/Accepted: 13 May 2011/Published online: 9 June 2011

(C) The Author(s) 2011. This article is published with open access at Springerlink.com

\begin{abstract}
Calculations were performed with the Earth system model of intermediate complexity LOVECLIM to study the response of the Greenland and Antarctic ice sheets to sustained multi-millennial greenhouse warming. Use was made of fully dynamic 3D thermomechanical ice-sheet models bidirectionally coupled to an atmosphere and an ocean model. Two 3,000-year experiments were evaluated following forcing scenarios with atmospheric $\mathrm{CO}_{2}$ concentration increased to two and four times the pre-industrial value, and held constant thereafter. In the high concentration scenario the model shows a sustained mean annual warming of up to $10^{\circ} \mathrm{C}$ in both polar regions. This leads to an almost complete disintegration of the Greenland ice sheet after 3,000 years, almost entirely caused by increased surface melting. Significant volume loss of the Antarctic ice sheet takes many centuries to initiate due to the thermal inertia of the Southern Ocean but is equivalent to more than $4 \mathrm{~m}$ of global sea-level rise by the end of simulation period. By that time, surface conditions along the East Antarctic ice sheet margin take on characteristics of the present-day Greenland ice sheet. West Antarctic ice shelves have thinned considerably from subshelf melting and grounding lines have retreated over distances of several $100 \mathrm{~km}$, especially for the Ross ice shelf. In the low concentration scenario, corresponding to a local warming of $3-4^{\circ} \mathrm{C}$, polar ice-sheet melting proceeds at a much lower rate. For the first 1,200 years, the Antarctic ice sheet is even slightly larger than today on account of increased accumulation rates but contributes positively to sea-level rise after that. The Greenland ice sheet loses mass at a rate equivalent to $35 \mathrm{~cm}$ of global sea level rise during the first 1,000 years increasing to $150 \mathrm{~cm}$ during the last 1,000 years. For both scenarios,
\end{abstract}

\footnotetext{
P. Huybrechts $(\bowtie) \cdot$ H. Goelzer $\cdot$ I. Janssens

Earth System Sciences and Departement Geografie, Vrije Universiteit Brussel, Brussels, Belgium e-mail: phuybrec@vub.ac.be

E. Driesschaert

Faculty of Sciences, Université Catholique de Louvain, Louvain-la-Neuve, Belgium

T. Fichefet $\cdot$ H. Goosse - M.-F. Loutre

Georges Lemaître Centre for Earth and Climate Research (TECLIM), Earth and Life Institute,

Université Catholique de Louvain, Louvain-la-Neuve, Belgium
} 
ice loss from the Antarctic ice sheet is still accelerating after 3,000 years despite a constant greenhouse gas forcing after the first 70-140 years of the simulation.

Keywords Ice sheets $\cdot$ Sea-level change $\cdot$ EMIC $\cdot$ Ice-climate interactions

\section{Introduction}

Sea-level changes are often mentioned as an important consequence of climate changes. Global temperatures have risen by about $0.8^{\circ} \mathrm{C}$ over the last 100 years concurrent with an average sea-level rise of about $20 \mathrm{~cm}$ (Solomon et al. 2007). By far the largest potential source for sea-level rise is made up by the Greenland and Antarctic ice sheets, which could raise global sea level by $70 \mathrm{~m}$ if melted entirely. Yet their current contribution to sea-level change is comparatively small and moreover prone to large uncertainties. Based on a variety of sources from remote sensing platforms and mass balance models, recent studies (Rignot et al. 2008a; Van den Broeke et al. 2009) estimate their combined total mass imbalance over the last decade at $-433 \pm 95 \mathrm{Gt} / \mathrm{year}$. That is equivalent to $1.1 \pm 0.2 \mathrm{~mm} /$ year of sea-level rise or $11 \pm 2 \mathrm{~cm}$ if sustained over a whole century, but the error bar could be larger. Ongoing and past glacier accelerations may account for up to half or more of this total mass trend over the last decade (Rignot et al. 2008b) but a precise attribution to either surface mass balance changes or ice flow changes can not yet confidently be made. Available model projections for the 21st century stress the dominant role of surface mass balance changes and the mitigating role of increased Antarctic accumulation in a warmer atmosphere (e.g. Huybrechts et al. 2004). Fast ice-flow variations such as those observed over the last 10-15 years could possibly be a significant fraction in the sea-level contribution from the polar ice sheets on the centennial time scale but are not routinely included in model projections as their mechanisms are badly understood, and therefore cannot be projected with confidence (Meehl et al. 2007).

Longer-term projections of the response of the polar ice sheets to future warming are best addressed in the framework of fully dynamic ice sheet models incorporated in climate models. On time scales of centuries to millennia, the ice sheets themselves exert influences on the atmosphere and the ocean that in turn affect their surface mass balance and melting rates at places where the ice is in contact with the ocean. Changes in orographic height and slope of the ice sheets potentially alter atmospheric flow patterns through their effect on planetary vorticity and planetary waves (in the case of Greenland), and on a regional scale through the modification of the katabatic wind system (both Antarctica and Greenland) (Lunt et al. 2004; Ridley et al. 2005). A second effect relates to changes in surface reflectivity of thinning and receding ice sheets. This essentially constitutes the ice-albedo feedback, which, by changing the radiation regime of the surface, potentially leads to an amplification of the initial temperature perturbation. At any rate, changes in ice sheet geometry affect the distribution of ice thickness and surface slope (driving stress), altering the ice flow and thus also the shape of the ice sheet. This in turn affects surface temperatures on the ice sheet, giving rise to a positive elevation-temperature feedback. Moreover, modeling evidence suggests that freshwater input from Greenland ice sheet runoff could potentially slow down the Atlantic meridional overturning circulation (AMOC) by changing the density of the ocean surface water (Fichefet et al. 2003), but the effectiveness of this feedback is still under debate. Jungclaus et al. (2006), Mikolajewicz et al. (2007b), Driesschaert et al. (2007), Hu et al. (2009) found only a small transient effect of increased Greenland melting on the AMOC that was either small compared to the effect of enhanced 
poleward atmospheric moisture transport or only noticeable in the most extreme scenarios. Ice-sheet ocean feedbacks in interactively coupled models have been found to slow down ice-sheet decay, but the effect is quite weak in most cases (Vizcaíno et al. 2008, 2010). By contrast, Swingedouw et al. (2008) and Goelzer et al. (2010) found that surface runoff and increased ice-shelf melting from the Antarctic ice sheet had a strong mitigating effect on the regional warming due to negative feedbacks arising from Antarctic Bottom Water formation and sea-ice formation.

Available model studies on the long-term fate of the polar ice sheets have mostly concentrated on the Greenland ice sheet, generally using a three-dimensional ice-sheet model coupled to climate models of varying complexity (e.g. Huybrechts and de Wolde 1999; Ridley et al. 2005; Charbit et al. 2008). These agree that the Greenland ice sheet will significantly decrease in area and volume in a warmer climate on account of increased melting outweighing increased accumulation. If the warming is maintained for a sufficiently long period, total decay of the ice sheet is predicted. Surface mass balance models suggest a threshold for the long-term viability of the ice sheet of between 1.9 and $4.6^{\circ} \mathrm{C}$ global mean annual warming (Gregory and Huybrechts 2006). Such a threshold is generally confirmed in coupled ice-sheet simulations. The temperature range may be larger when additional uncertainty from the melt model is included (Bougamont et al. 2007); however, Stone et al. (2010) find the threshold to be substantially lower using new boundary conditions for ice-sheet geometry, surface temperature and precipitation. For sustained $4 \times \mathrm{CO}_{2}$ forcing, corresponding to a mean Greenland warming of around $8^{\circ} \mathrm{C}$, Ridley et al. (2005) find deglaciation to take around 3,000 years to complete using HadCM3. Similar rates of mass loss for comparable warmings were also obtained with the Hamburg Earth System Model (Mikolajewicz et al. 2007a, b; Vizcaíno et al. 2008, 2010), although they used a different set of climate scenarios.

Because of the positive climate feedbacks on ice-sheet decline, subsequent cooling below the threshold of sustainability may not regrow the ice sheet to its original size, indicative of hysteresis. This was investigated by Ridley et al. (2010) with a high-resolution ice-sheet model coupled to HadCM3. They found that the present-day ice sheet could be reformed only if the volume had not fallen below a threshold of irreversibility, which lay between 80 and $90 \%$ of the original value. Depending on the degree of warming, this threshold of irreversibility could be reached within several hundred years, sooner than global climate could revert to a pre-industrial state. Taking into account the long time it takes to remove atmospheric $\mathrm{CO}_{2}$ by the Earth system, Charbit et al. (2008) linked irreversible decay of the Greenland ice sheet to a cumulative $\mathrm{CO}_{2}$ emission above $3,000 \mathrm{GtC}$. For smaller emissions, the Greenland ice sheet could still recover over a period of several thousand years.

Compared to the mainly land-based Greenland ice sheet, the Antarctic ice sheet is surrounded by large ice shelves in contact with the ocean. The relevant quantities controlling sea-level changes therefore include changes in discharge from the grounded ice sheet into the ice shelves and grounding-line migration, which processes are affected by changes in melting below the ice shelves and buttressing effects from their shear margins (Huybrechts and de Wolde 1999). These mechanisms are missing from Earth System Models that include Antarctic models without ice shelf dynamics (Mikolajewicz et al. 2007a, b; Vizcaíno et al. 2008, 2010), and which find that the Antarctic ice sheet contributes negatively to global sealevel under a wide range of warming scenarios because of increased snowfall.

In this paper we discuss two 3,000-year simulations concentrating on the behavior of the Greenland and Antarctic ice sheets with the Earth System Model of Intermediate Complexity LOVECLIM (Goosse et al. 2010). Compared to other EMICs, this model includes fully dynamic 3-D ice-sheet models at high resolution (10 km horizontal grid size), 
allowing a better representation of the ice flow at ice-sheet margins. The Antarctic ice sheet component additionally incorporates coupled ice-shelf flow, grounding-line migration and a parameterization for ice-shelf melt to account for ice-ocean interactions. All relevant mutual interactions between the various climate components (atmosphere, ocean, vegetation) are considered, except for the carbon cycle that is not active in this study. In the following we describe the LOVECLIM model (Sect. 2) and the experimental design (Sect. 3). The results are discussed separately for the Greenland and Antarctic ice sheets in Sect. 4, followed by a concluding section (Sect. 5). These results complement two other studies performed with the same model configuration (Driesschaert et al. 2007; Swingedouw et al. 2008) but which did not analyze the response of the ice sheets and their contribution to global sea level in detail.

\section{Model Description}

\subsection{LOVECLIM}

The results discussed in this paper are based on LOVECLIM version 1.0 in the same set up as described in Driesschaert et al. (2007) and Swingedouw et al. (2008). A slightly updated version of the model was recently released as version 1.2 (Goosse et al. 2010). Most of the modifications to the code were of a technical nature with no impact on the results and do not affect the details of the ice-climate interactions of interest here. Therefore only a brief overview of the model is given here. Figure 1 schematically shows all model components and their mutual interactions. The model includes components for the atmosphere (ECBilt), the ocean and sea-ice (CLIO), the terrestrial biosphere (VECODE), the carbon cycle (LOCH) and the Antarctic and Greenland ice sheets (AGISM). ECBilt (Opsteegh et al. 1998) is a spectral atmospheric model with truncation T21, which corresponds approximately to a horizontal resolution of $5.625^{\circ}$ in longitude and latitude, and incorporates three vertical levels. It includes simple parameterizations of the diabatic heating processes and an explicit representation of the hydrological cycle. Cloud cover is prescribed according to the present-day climatology. CLIO_Coupled Large-scale Ice-Ocean model—is a global freesurface ocean general circulation model coupled to a thermodynamic sea-ice model (Fichefet and Morales Maqueda 1997; Goosse and Fichefet 1999; Goosse et al. 1999). The horizontal resolution of CLIO is $3^{\circ}$ in longitude and latitude, and there are 20 unevenly spaced levels in the vertical. VECODE_-VEgetation COntinuous DEscription model-is a reduced-form model of the vegetation dynamics and of the terrestrial carbon cycle (Brovkin et al. 1997). It is based on a continuous bioclimatic classification: every land grid cell is covered by a mixture of grass, forest and desert. LOCH-Liège Ocean Carbon Heteronomous model (Mouchet and François 1996) is a comprehensive, three-dimensional oceanic carbon cycle model subject to external controls. Since the evolution of $\mathrm{CO}_{2}$ concentration was prescribed in the present simulations, the carbon cycle component of the model was used in diagnostic mode and its results are not discussed here.

\subsection{The Ice Sheet Model}

AGISM (Antarctic and Greenland Ice Sheet Model) consists of two three-dimensional thermomechanical ice-dynamic models for each of the polar ice sheets. Both models are based on the same physics and formulations, however with the major distinction that the Antarctic component incorporates a coupled ice shelf and grounding line dynamics. Ice 


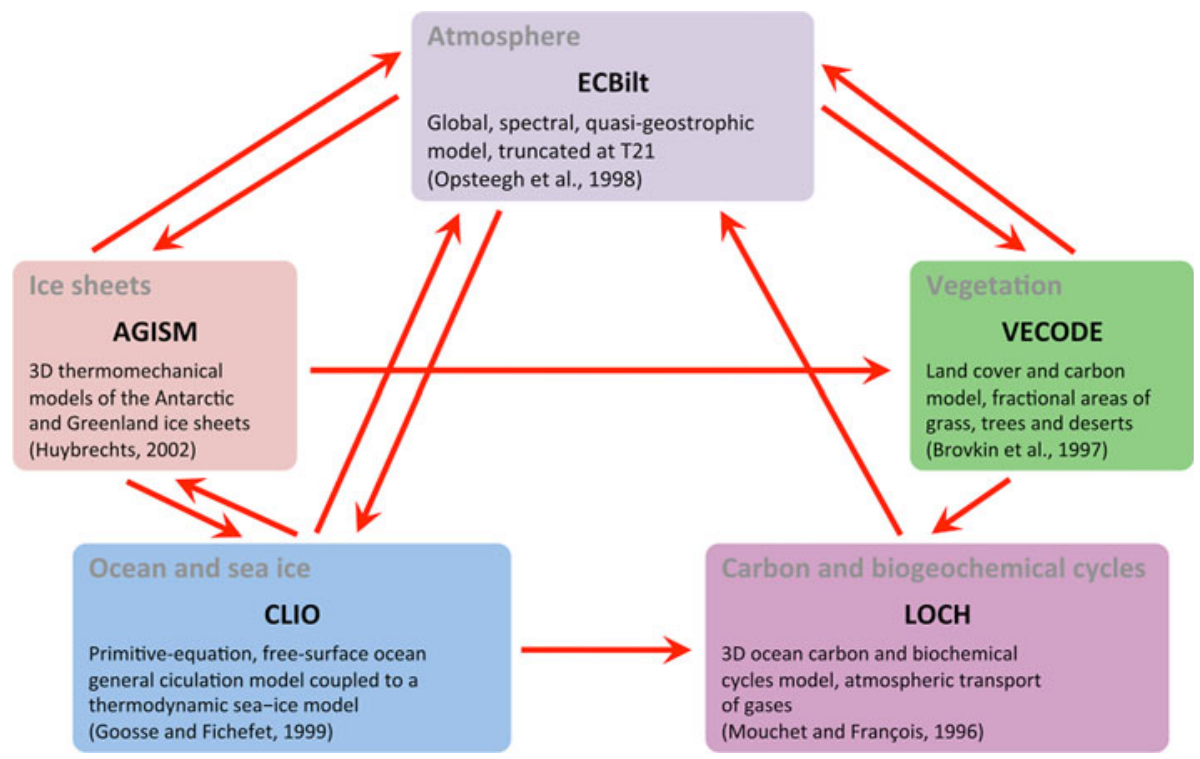

Fig. 1 Scheme of the LOVECLIM model showing the interactions between the five components. In this study, the LOCH component is not active

shelf dynamics is missing from the Greenland component as there is hardly any floating ice under present-day conditions, and this can be expected to disappear quickly under warmer conditions. Having a melt margin on land or a calving margin close to its coast for most of its glacial history, ice shelves probably played a minor role for Greenland also during colder conditions.

Both polar ice sheet models consist of three main components, which, respectively, describe the ice flow, the solid Earth response, and the mass balance at the ice-atmosphere and ice-ocean interfaces (Huybrechts and de Wolde 1999; Huybrechts 2002; Goosse et al. 2010; to which papers the interested reader is referred to for a full overview of all equations and model formulations). Figure 2 shows the structure of the models.

In the models, the flow is calculated both in grounded ice and, for Antarctica, in a coupled ice shelf to enable free migration of the grounding line. The flow is thermomechanically coupled by simultaneous solution of the heat equation with the velocity equations, using Glen's flow law and an Arrhenius-type dependence of the rate factor on temperature. In grounded ice, the flow results from both internal deformation and sliding over the bed in places where the temperature reaches the pressure melting point and a lubricating water layer is present. Longitudinal deviatoric stresses are disregarded according to the widely used 'Shallow Ice Approximation'. This does not treat the rapid component of the otherwise badly understood physics specific to fast-flowing outlet glaciers or ice streams. For the sliding velocity, a generalized Weertman relation is adopted, taking into account the effect of the subglacial water pressure. Ice shelves are included by iteratively solving a coupled set of elliptic equations for ice shelf spreading in two dimensions, including the effect of lateral shearing induced by sidewalls and ice rises. At the grounding line, longitudinal stresses are taken into account in the effective stress term of the flow law. These additional stress terms are found by iteratively solving three coupled equations for depth-averaged horizontal stress deviators. 


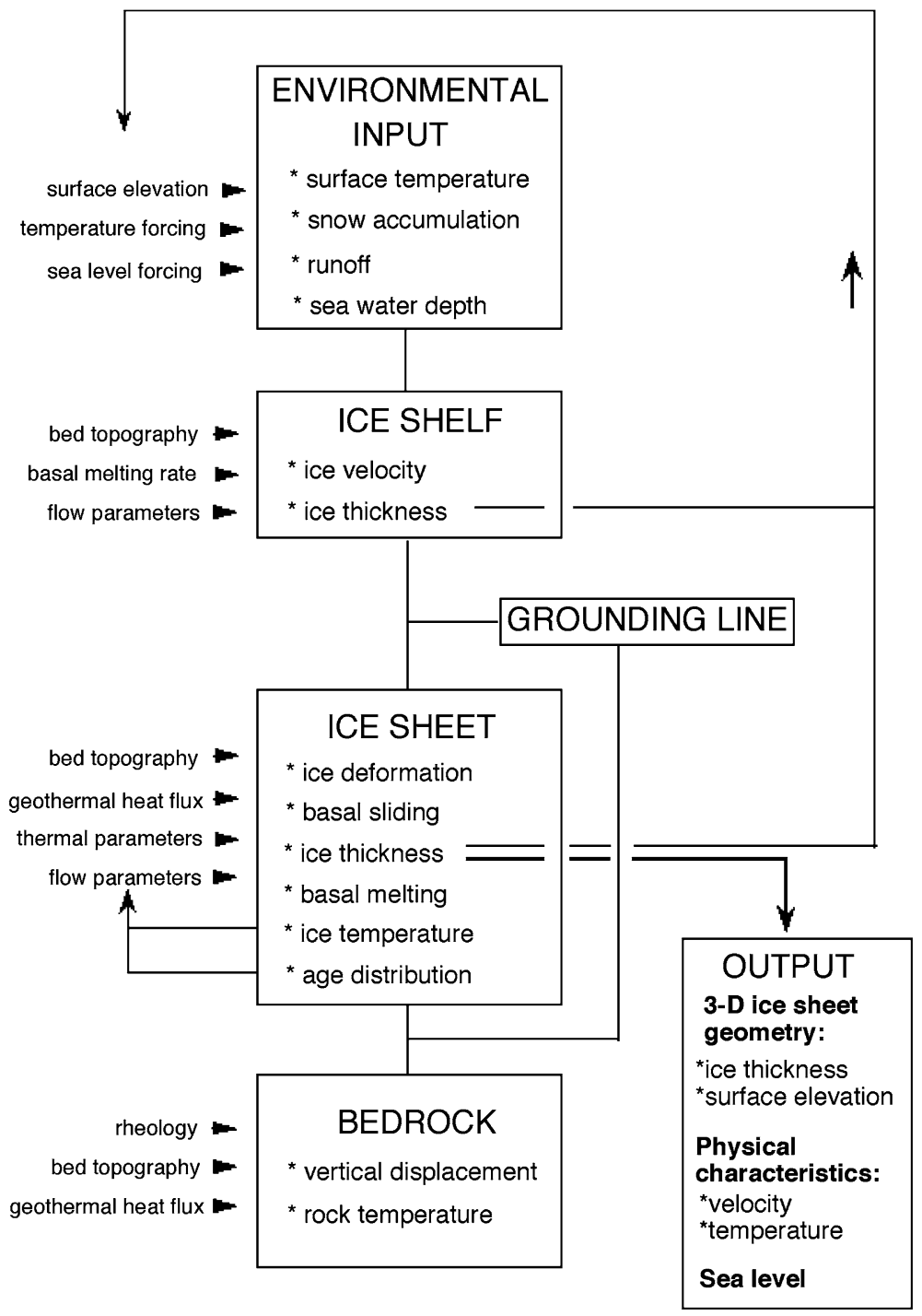

Fig. 2 Structure of the three-dimensional thermodynamic ice sheet model AGISM. The inputs are given at the left-hand side. Prescribed environmental variables drive the model, which incorporates ice shelves, grounded ice and bed adjustment as its major components. Regarding the Antarctic component, the position of the grounding line is not prescribed, but internally generated. The model essentially outputs the timedependent ice sheet geometry and the associated temperature and velocity fields

Isostatic compensation of the bedrock is taken into account for its effect on bed elevation near grounding lines and marginal ablation zones, where it matters most for ice sheet dynamics, and because isostasy enables ice sheets to store 25-30\% more ice than evident from their surface elevation alone. The bedrock adjustment model consists of a viscous asthenosphere, described by a single isostatic relaxation time, which underlies a rigid elastic plate (lithosphere). The crustal loading takes into account contributions from 
both ice and ocean water within the respective numerical grids, but ignores any ice loading changes beyond the Greenland and Antarctic continental areas.

For both ice sheets, calculations are made on a $10 \times 10 \mathrm{~km}$ horizontal resolution, with 31 vertical layers in the ice and another 9 layers in the bedrock for the calculation of the heat conduction in the crust. The vertical grid in the ice has a closer spacing near to the bedrock where the shear concentrates. Rock temperatures are calculated down to a depth of $4 \mathrm{~km}$. This gives rise to between 1.85 and $12.6 \times 10^{6}$ grid nodes for Greenland and Antarctica, respectively. Geometric datasets for surface elevation, ice thickness and bed elevation incorporate most of the recent observations up to 2001, such as ERS-1 derived satellite heights, BEDMAP and EPICA pre-site survey Antarctic ice thicknesses and the University of Kansas collection of airborne radio-echo-sounding flight tracks over Greenland (Huybrechts and Miller 2005). The grids correspond to those discussed in Huybrechts and Miller (2005) and include modifications in marginal ice thickness around Greenland margins to remove known artefacts when subtracting an ice thickness field constructed for a more limited mask than the actual ice sheet surface elevation. Overdeepened fjord beds of important outlet glaciers were added manually when absent from the interpolated fields, both for Antarctica and Greenland. The $10 \mathrm{~km}$ horizontal resolution substantially improves the representation of the fast-flowing outlet glaciers and ice streams, which are responsible for the bulk of the ice transport towards the margin. Other physics specific to these features such as higher-order stress components or subglacial sediment characteristics are not included, in common with the current generation of three-dimensional ice-sheet models.

Interaction with the atmosphere and the ocean is effectuated by prescribing the climatic input, consisting of the surface mass balance (accumulation minus ablation), surface temperature and the basal melting rate below the ice shelves surrounding the Antarctic component. The mass balance model distinguishes between snow accumulation, rainfall and meltwater runoff, which components are all parameterized in terms of temperature. The melt- and runoff model is based on the positive degree-day method and is identical to the recalibrated version as described in Janssens and Huybrechts (2000) with a noticeable typing correction to the exponent in the calculation of the expected sum of positive degree days (Goosse et al. 2010). Meltwater is at first retained in the snowpack by refreezing and capillary forces until the pores are fully saturated with water, at which time runoff can occur. This method to calculate the melt has been shown to be sufficiently accurate for most practical purposes. It moreover ensures that the calculations can take place on the detailed grids of the ice-sheet models so that one can properly incorporate the feedback of local elevation changes on the melt rate, features which cannot be represented well on the generally much coarser grid of a climate model. The melt model is also implemented for Antarctica, but since current summer temperatures remain generally below freezing, melt amounts are currently negligible there. Because of their very low surface slopes, it is further assumed that melt water produced on the surface of the Antarctic ice shelves, if any, refreezes in situ at the end of the summer season, and therefore does not runoff to the ocean. Below the ice shelves, a uniform melting rate is applied which magnitude is linked to the heat input into the cavity, as explained in Sect. 2.3. For the experiments discussed in this paper, AGISM parameters are the same as those listed in Table 5 in Goosse et al. (2010).

\subsection{Climate-Ice Sheet Interactions}

The key atmospheric variables needed as input for AGISM are monthly surface temperature and annual precipitation. Because the details of the Greenland and Antarctica surface 
climate are not well captured on the ECBilt coarse grid, these boundary conditions consist of present-day observations as represented on the much finer AGISM grid onto which climate change anomalies from ECBilt are superimposed. Monthly temperature differences and annual precipitation ratios, computed against a reference climate corresponding to the period 1970-2000 AD, are interpolated from the ECBilt grid onto the AGISM grid and added to and multiplied by the parameterized surface temperatures and observed precipitation rates, respectively. The anomaly approach avoids systematic errors in the absolute ECBilt fields and ensures that some processes, such as the melting taking place at the ice sheet margin over a spatial extent narrower than the atmospheric model resolution, can be adequately represented.

The ocean heat flux at the base of Antarctic ice shelves is also calculated in perturbation mode based on a parameterization proposed by Beckmann and Goosse (2003):

$$
M(t)=\frac{Q^{\text {net }}(t)}{Q_{0}^{\text {net }}} \frac{A_{0}}{A(t)} M_{0}
$$

where $M$ is the basal melt rate, $Q^{n e t}$ an estimate of the total heat flux entering the ice shelves integrated all along the perimeter of Antarctica, and $A$ the total area of Antarctic ice shelves. Here the subscripts $t$ and 0 refer to the actual model time and the reference time taken as $1500 \mathrm{AD}$, respectively. In this approach the melt rate below the ice shelves depends on the net heat input from the oceans into the cavity below the ice shelves. The total melt volume is proportional to changes in the net integrated ocean heat input but inversely proportional to the area of the ice shelves. The underlying assumption is that much of the water in the cavity is recycled locally forming a semi-closed circulation cell. $Q^{\text {net }}$ is estimated directly from the mean ocean temperature around Antarctica.

After performing mass balance and ice dynamic computations, AGISM transmits the calculated changes in orography and land fraction covered by ice to ECBilt and VECODE, and the total freshwater flux to CLIO, as described further in Goosse et al. (2010). The anomaly coupling technique leads to heat and water losses/gains in the coupled model of the order of 10-25\% maximally. Flux adjustments are applied to ensure strict conservation of heat and water. This ensures the closure of the heat and water balances in the coupled system.

\section{Experimental Design}

To illustrate the response of both polar ice sheets under global warming, we performed two idealized experiments sampling a plausible range of longer-term climate conditions. First the Greenland (Antarctic) ice sheet modules were integrated over the last two (four) glacial cycles up to $1500 \mathrm{AD}$ with forcing from ice and sediment core data to derive initial conditions for coupling with the other components of LOVECLIM. Basal melting below the ice shelves was forced to follow the Vostok temperature forcing using the parameterization given in Huybrechts (2002) for a reference value of $M_{0}=0.25 \mathrm{~m} \mathrm{year}^{-1}$ for present-day conditions. The initialization experiments were first conducted on $20 \mathrm{~km}$ grid resolution to save computing time. At the time of the Last Glacial Maximum (19 kyr BP), all relevant data were interpolated on a $10 \mathrm{~km}$ resolution grid for the subsequent simulation of the glacial-interglacial transition and all of the Holocene. Hence, the outcome of the spin-up procedure are Greenland and Antarctic sheets at $1500 \mathrm{AD}$ that are not in steady state as they carry the long term memory of their history with them, but are fully equilibrated (no model drift) to the model physics and the input data. These ice sheet 

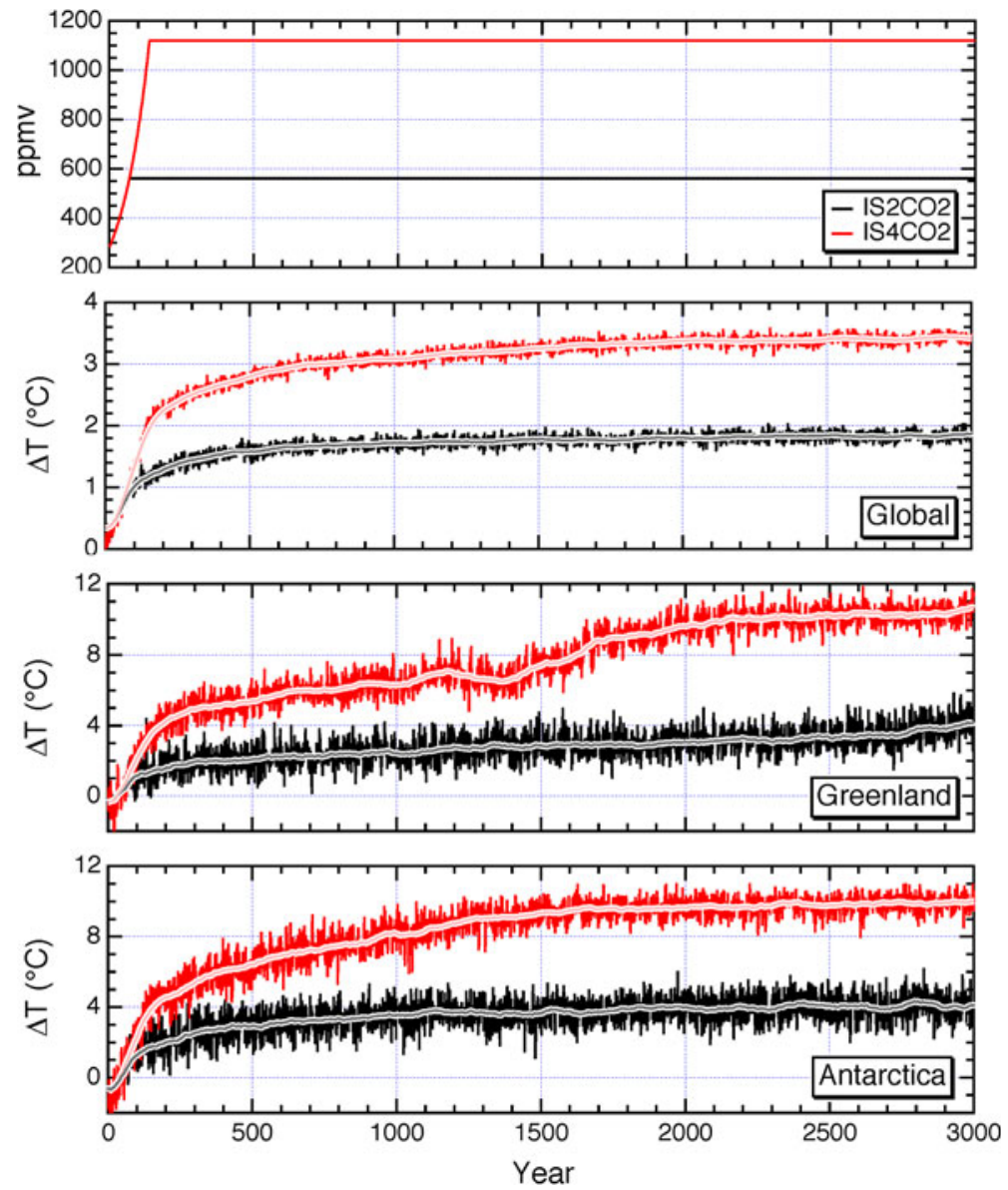

Fig. 3 The experiments employed two $\mathrm{CO}_{2}$ forcing scenarios, respectively doubling (IS2CO2, black lines) and quadrupling (IS4CO2, red lines) the pre-industrial concentration of $280 \mathrm{ppmv}$. Shown are the corresponding time evolution of the $\mathrm{CO}_{2}$ concentration, global mean annual temperature, and mean annual temperature over Greenland and Antarctica. The lower three panels display the full yearly variability of mean temperature around the 100 years running mean

configurations were used from $1500 \mathrm{AD}$ onward in coupled mode. The resulting background evolution has been analyzed by means of a control experiment, conducted with LOVECLIM under forcing conditions corresponding to the year $1500 \mathrm{AD}$. The background trend of volume changes is, however, negligible compared to the strong changes imposed by the $\mathrm{CO}_{2}$ forcing (not shown).

Two greenhouse warming experiments starting from the year 1500 conditions were performed. In IS2CO2 (IS4CO2), the $\mathrm{CO} 2$ concentration increases by $1 \%$ per year (compounded) until it reaches twice (four times) its initial value and remains unchanged for almost 3,000 years. The two forcing scenarios are illustrated in Fig. 3 along with the corresponding mean temperature changes over Greenland and Antarctica, and in the global mean. Global mean temperature changes are 1.8 and $3.4^{\circ} \mathrm{C}$ in IS2CO2 and IS4CO2, respectively, indicating a low climate sensitivity of our model compared to the IPCC AR4 best estimate of $3^{\circ} \mathrm{C}$ (Solomon et al. 2007). The change of mean annual temperature over 
Greenland and Antarctica is around 4 and $10^{\circ} \mathrm{C}$ at the end of both simulations, respectively, half of which is reached within the first two to three centuries (Fig. 3). These temperature increases are about a factor 2.2 and 2.9 higher than the global average because of the polar amplification seen in LOVECLIM. Such a polar amplification is a robust characteristic of the climate system but is stronger in LOVECLIM than in most other models. Gregory and Huybrechts (2006) typically found a polar amplification of around 1.5 for a representative suite of IPCC AOGCMs. The higher polar amplification of LOVECLIM combines with its lower climate sensitivity to yield polar temperature changes for a given radiative forcing that are in line with more comprehensive AOGCMs. Interestingly, the simulated climate warming over Greenland in scenario IS4CO2 shows a small weakening between the year 1150 and 1400 followed by a stepwise increase to the year 1700. These features are linked to ice-sheet climate interactions. The first feature occurs shortly after the freshwater peak from Greenland, which induces a weakening of the AMOC by about $25 \%$ as discussed in similar experiments in Driesschaert et al. (2007) and Swingedouw et al. (2008). The subsequent stepwise warming is a direct response to the exposure of a critical amount of ice free land with a lower albedo when the ice sheet has lost about $65 \%$ of its volume and its area (see also further).

\section{Results}

The results are analyzed in most detail for the high scenario IS4CO2 as these span the full spectrum of expected behavior for a disintegrating ice sheet. Most attention is paid to the time evolution of relevant mass balance characteristics.

\subsection{Greenland Ice Sheet}

Figure 4 shows the implications for the Greenland ice sheet of a sustained warming averaging $+8^{\circ} \mathrm{C}$ over a period of 3,000 years. Surface runoff from the ice sheet is affected most and rapidly dominates the total fresh water flux from Greenland. Critical is the ratio of total ablation to total accumulation over the ice sheet. Whereas for present-day conditions the total volume of melt water runoff is about half the volume of snow accumulation, a balanced surface mass budget (accumulation $=$ ablation) is reached after 120 years of rising $\mathrm{CO}_{2}$ concentrations at a time when the mean annual warming over Greenland is about $+2.5^{\circ} \mathrm{C}$. This threshold is fully in line with inferences from mass-balance models (e.g. Oerlemans 1991; Janssens and Huybrechts 2000), and approximately marks the limit of viability of the ice sheet. For a larger warming, the Greenland ice sheet can no longer be sustained, even when the calving flux were reduced to zero (Gregory et al. 2004). The latter effectively occurs later in the simulation after 500 years of warming when the ice sheet no longer borders the coastline in contact with ocean water. After 120 years, the calving rate is reduced by $50 \%$. One of the implications is that marginal erosion of calving fronts by warmer ocean water, often considered a plausible explanation for the observed fast velocity changes in many outlet glaciers (e.g. Rignot and Kanagaratnam 2006), will gradually disappear as a potentially meaningful mechanism for ice loss in a warmer climate. Basal melting from below the Greenland ice sheet, on the other hand, always is a very minor contributor to the total freshwater budget from Greenland. Snow accumulation over the ice sheet remains almost constant for the first 1,000 years of the experiment (not shown) as the increased precipitation expected for a warmer climate is counterbalanced by both an increased fraction falling as rain and a decreasing ice-sheet area. 

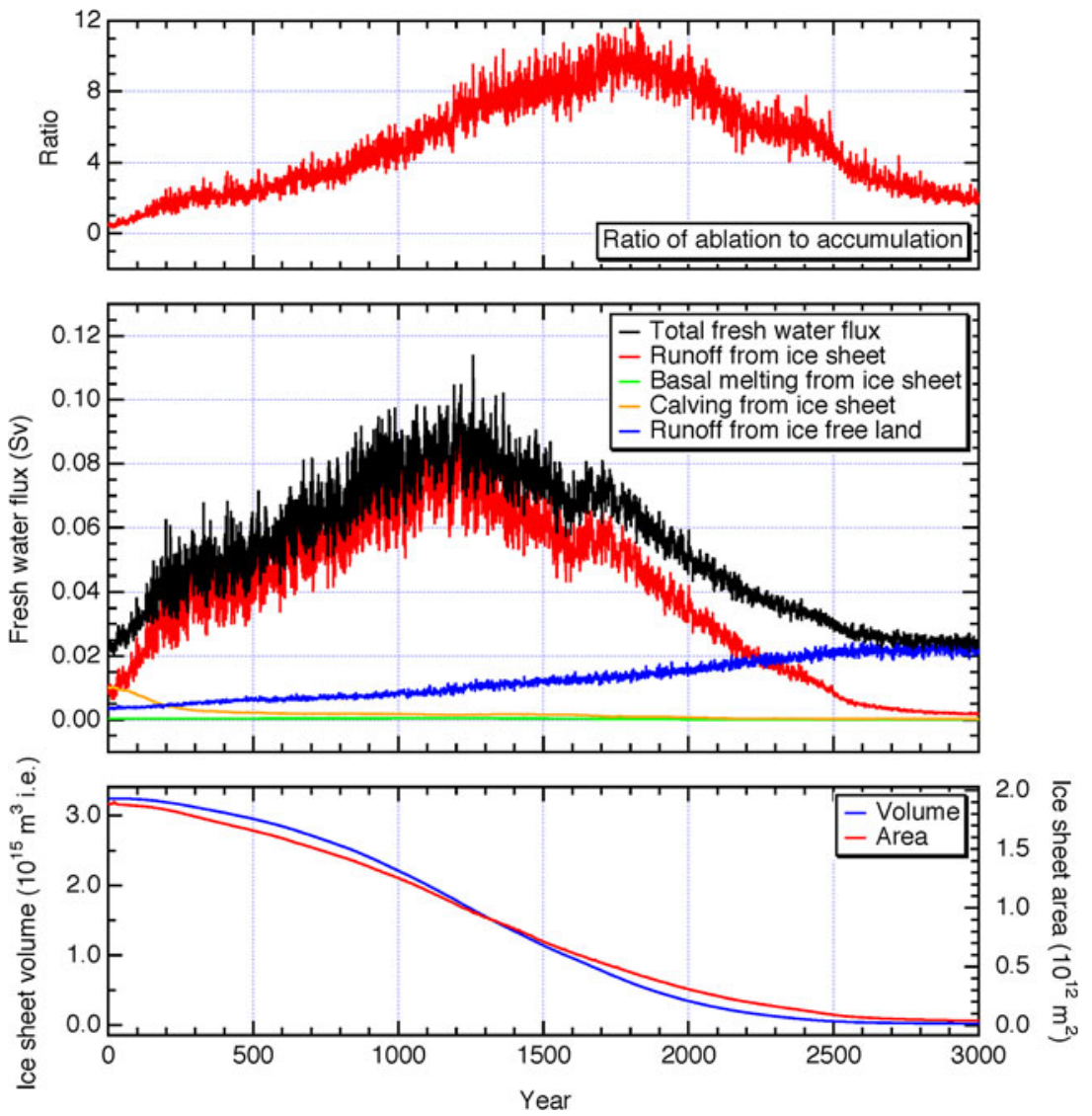

Fig. 4 Response characteristics of the Greenland ice sheet to scenario IS4CO2 during 3,000 years. Shown are changes in mass balance components and ice sheet size. The total freshwater flux derives from all of Greenland and is further divided in its components. Values are expressed in Sverdrup $\left(1 \mathrm{~Sv}=1 \times 10^{6} \mathrm{~m}^{3} \mathrm{~s}^{-1}\right)$

The gradual melting of an ice reservoir containing enough ice to raise sea level by $\sim 7.5 \mathrm{~m}$ causes peak runoff rates approaching $0.1 \mathrm{~Sv}$ after more than 1,000 years of sustained warming, corresponding to a tenfold increase. After that, the ice sheet becomes considerably smaller, and the runoff flux decreases rapidly. At the end of the 3,000 years of simulated Greenland ice sheet evolution, the ice sheet has almost completely melted away. Runoff from the remaining small cap is negligible and the total freshwater flux derives almost entirely from the yearly runoff from the ice-free tundra. The total freshwater flux originating from melting of the Greenland ice sheet induces a transient weakening of the AMOC strength by 10-25\% that starts after 1,200 years and lasts for $~ 500$ years (not shown). Such behavior is in line with previous results obtained with the same model but for a slightly different climate scenario (Driesschaert et al. 2007). The reduction of the associated meridional heat transport is visible in the mean annual temperature response over the Greenland ice sheet (Fig. 3) and therefore exemplifies a (transient) negative feedback mechanism.

Snapshots of the retreating Greenland ice sheet for IS4CO2 are shown in Fig. 5. The ice sheet retreat first occurs in the southwest, where already today a $300 \mathrm{~km}$ wide band of 

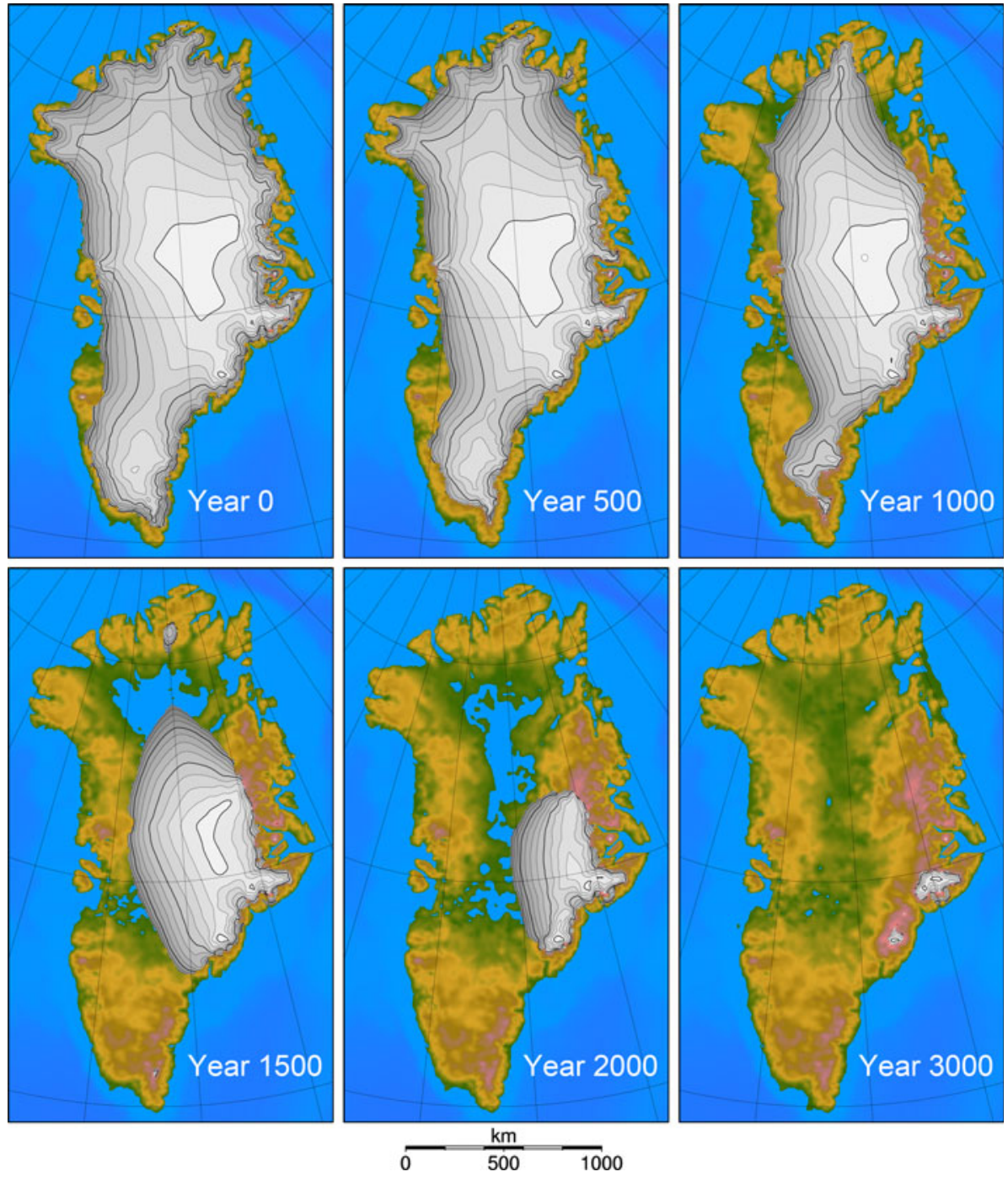

1000

Fig. 5 Snapshots of Greenland ice sheet evolution under scenario IS4CO2. The ice sheet is represented by grey shading, ice-free land by brown and green colours and ocean and land below sea level in blue. Contour interval over the ice sheet is $250 \mathrm{~m}$, with thick lines for every $1,000 \mathrm{~m}$ of surface elevation

tundra is present. After several centuries the Greenland ice sheet becomes fully land-based. The central dome survives longest at an almost constant elevation of around 3,000 m. This makes the ice sheet flanks steeper and the ice flow faster to accommodate for the higher mass balance gradients in a warmer climate. The steeper margins represent a counteracting effect on the ice sheet retreat. They dynamically reduce the area below the equilibrium line and thus reduce the area over which runoff can take place. Compared to experiments without this effect, the ensuing rate of ice sheet decay has been found in earlier studies to be about 20\% smaller (Huybrechts and de Wolde 1999; Huybrechts et al. 2004). The ice sheet ultimately retreats to the easterly mountain range, gradually exposing bare land that 

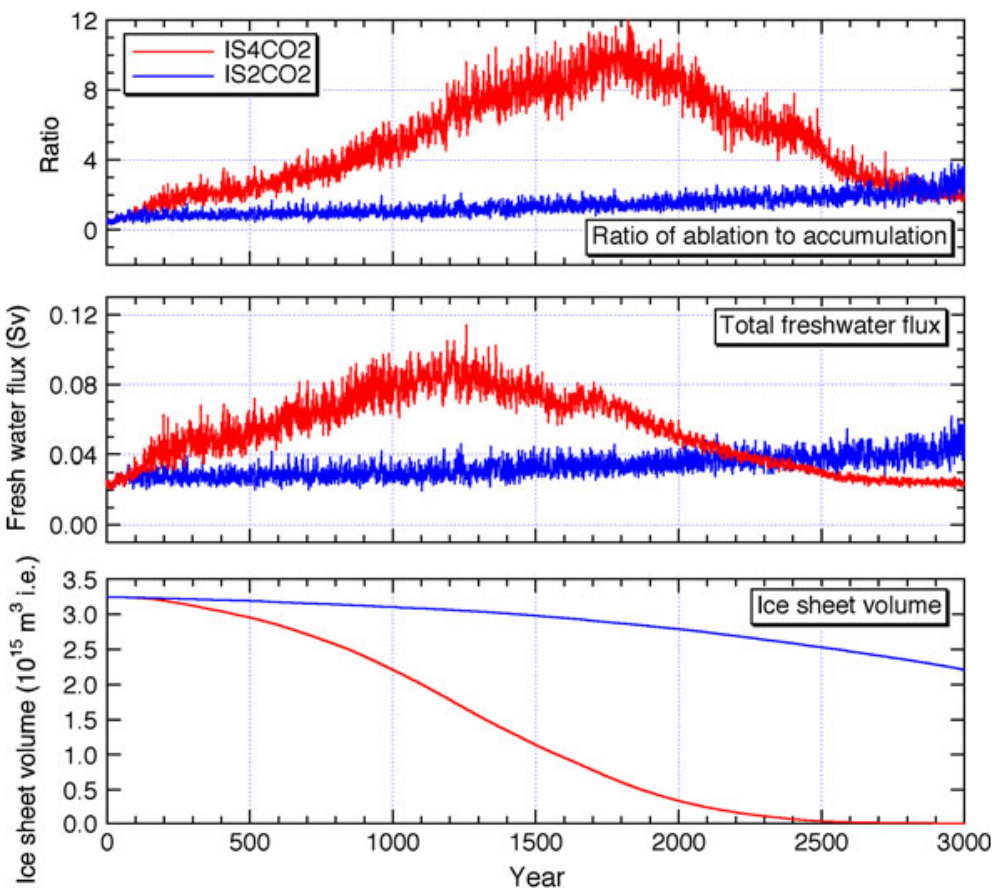

Fig. 6 Response of the Greenland ice sheet to scenario IS2CO2 (blue lines) compared to scenario IS4CO2 (red lines) during 3,000 years. Shown are changes in ice sheet volume and general mass balance characteristics. The total freshwater flux is expressed in Sverdrup $\left(1 \mathrm{~Sv}=1 \times 10^{6} \mathrm{~m}^{3} \mathrm{~s}^{-1}\right)$

experiences more summer heating than the adjacent ice sheet because of its lower albedo. Initially, the retreating ice sheet unveils a series of large inland depressions on bed below sea level that are likely candidates for (proglacial) lakes. Most of them are shallow and have no direct connection to the ocean. However, the removal of ice enables the bedrock to slowly rebound with its characteristic millennial time scale. After 3,000 years of simulation, most initial sub-sea-level areas have risen above sea level.

As can be inferred from Fig. 6, the relation between the strength of the climate warming and the disintegration characteristics of the Greenland ice sheet is clearly non-linear. After 3,000 years in the IS2CO2 experiment, with approximately half of the temperature increase seen in IS4CO2, ice volume and mass balance characteristics are comparable to the situation for IS4CO2 after 1,000 years. Surface melting in IS2CO2 is steadily increasing throughout the whole experiment and even accelerating at the end, when temperatures over Greenland start rising again (Fig. 6). The reasons for this are positive ice-albedo and elevation-temperature feedbacks that lead to increasing surface temperatures long after the atmospheric $\mathrm{CO}_{2}$ concentration has saturated.

\subsection{Antarctic Ice Sheet}

Surface runoff from the Antarctic ice sheet is a negligible component of the Antarctic mass balance in a pre-industrial climate and remains very small for the first 100 years of the IS4CO2 simulation as long as the warming does not exceed $2^{\circ} \mathrm{C}$ (Fig. 7). However, this component gradually becomes more important as temperature rises further at an almost 

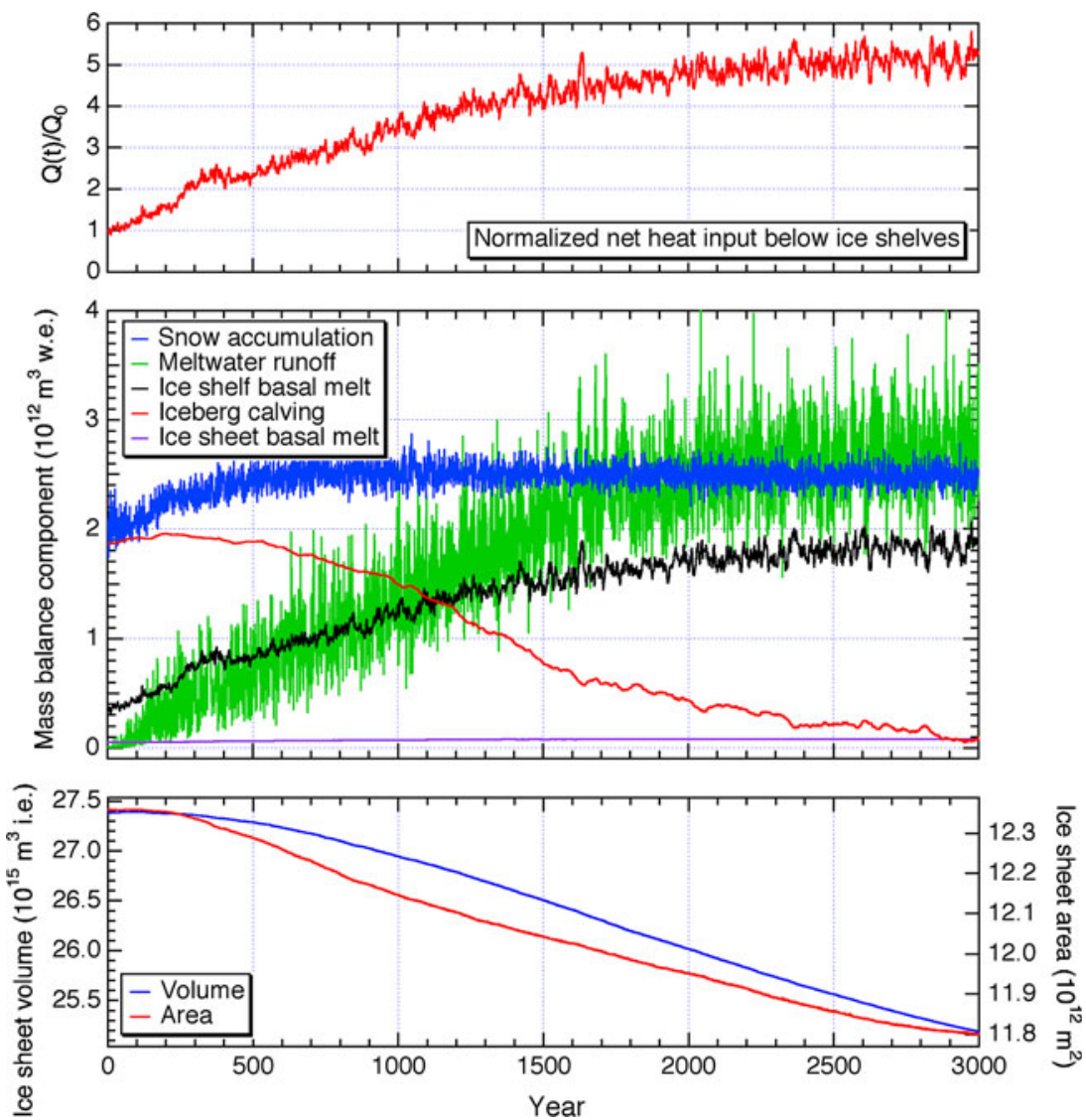

Fig. 7 Response characteristics of the Antarctic ice sheet to scenario IS4CO2 during 3,000 years. Shown are changes in mass balance components and the ensuing changes in ice sheet size

linear rate for about 1,500 years. An approximately balanced surface budget occurs after 2,000 years when the mean annual warming exceeds $10^{\circ} \mathrm{C}$, in line with older studies (Huybrechts and de Wolde 1999). As a consequence, surface conditions along the Antarctic ice sheet margin eventually take on characteristics of the present-day Greenland ice sheet. Visual inspection of the associated mass-balance patterns brought to light that the ablation zone develops mainly around the low-lying perimeter of the East Antarctic ice sheet and along the Antarctic Peninsula but that the inland portions of the West Antarctic ice sheet (including the grounding zones of the large ice shelves) largely remain in the accumulation zone. The increase in snow accumulation by $\sim 25 \%$ during the first 1,000 years when most of the precipitation falls as snow is weaker in LOVECLIM than dictated by the Clausius-Clapeyron relation and about half that obtained from time slice simulations with AOGCMs (Huybrechts et al. 2004).

A striking aspect of the melt curves shown in Fig. 7 is the gradual increase at an almost linear rate for the first 2,000 years of the simulation. This is explained by the thermal inertia of the Southern Ocean, which delays the warming around Antarctica on a multicentennial time scale. This is an important aspect to consider when discussing the response of the Antarctic ice sheet to greenhouse gas warming. The effect is obvious in both the 
increase of surface runoff, linked to coastal surface temperatures, and basal melting below the ice shelves. The latter is assumed proportional to the oceanic heat input integrated around Antarctica. The ocean warming continues long after greenhouse gas concentrations have stabilized, and is consistent with typical oceanic adjustment time scales.

The iceberg calving flux, calculated as the volume flux through a predefined dynamic ice shelf mask, is found to slightly increase during the first 200 years consistent with an increased accumulation rate and slightly higher ice shelf temperatures. After 500 years, ice shelf thinning from increased basal melting and reduced feeding of ice shelves from the grounded ice sheet as surface ablation increases, causes the iceberg flux to gradually decline to around 5\% of its initial value by the year 3000. Taken together, the induced mass balance changes cause the Antarctic ice sheet to grow slightly during the first 100 years of experiment IS4CO2, whereafter grounding line retreat and marginal ice thinning set in. After 3,000 years in a $+10^{\circ} \mathrm{C}$ climate, the Antarctic ice sheet has lost about $8 \%$ of its ice volume and $5 \%$ of its grounded ice sheet area (Fig. 7). The mechanisms responsible for groundingline retreat in the Antarctic ice sheet model have been described elsewhere (Huybrechts and de Wolde 1999) and include strain softening near the grounding line, decreased ice fluxes from the grounded ice and a lower effective viscosity of a warmer ice shelf. Basal melting from below the grounded ice sheet is a negligible contributor to the mass balance of the Antarctic ice sheet at all times, as it is for the Greenland ice sheet.

Snapshots from Antarctic ice sheet evolution in scenario IS4CO2 are displayed in Fig. 8. The most important change is grounding-line retreat around the WAIS, especially in the Ross sector, and along overdeepened glaciers of the EAIS. On the millennial time scale considered here, elevations in central East Antarctica remain largely unaffected, although
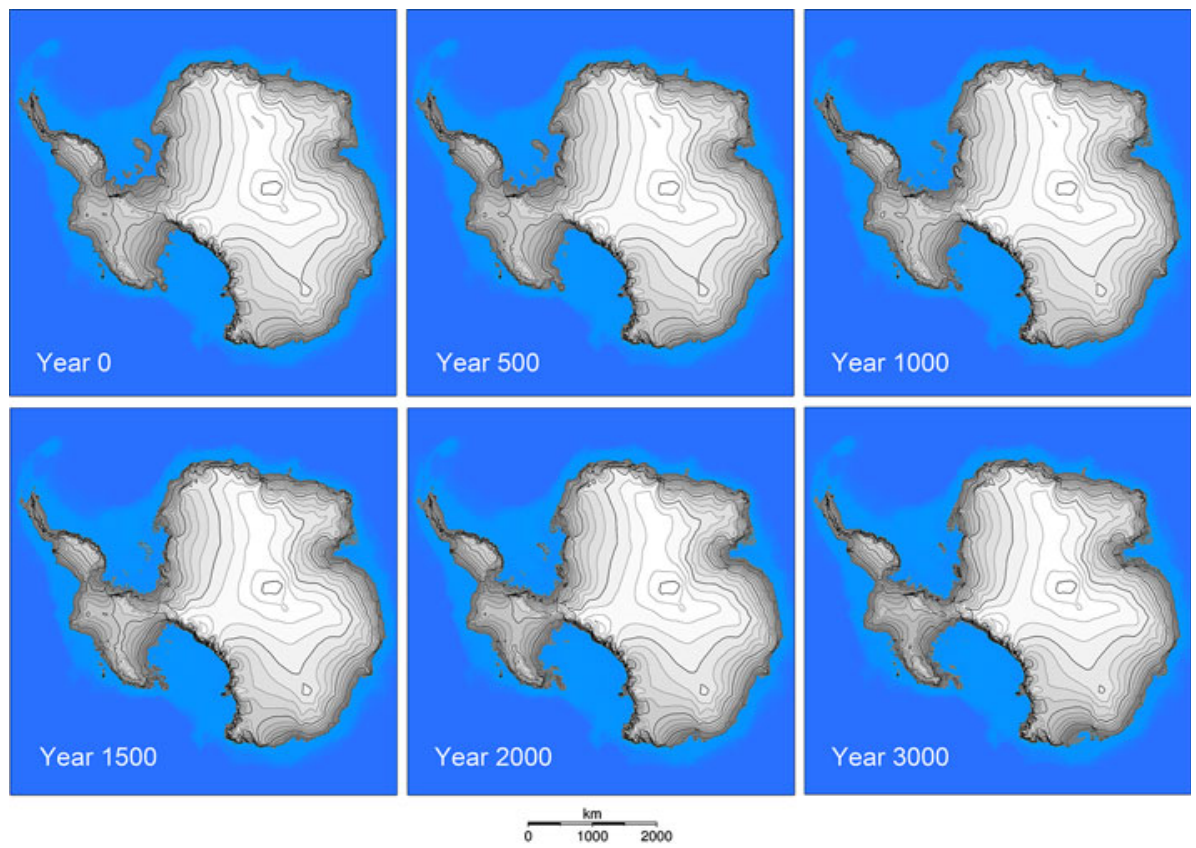

Fig. 8 Snapshots of Antarctic ice sheet evolution under scenario IS4CO2. Grey shading represents grounded ice. Contour interval is $250 \mathrm{~m}$, with thick lines for every $1,000 \mathrm{~m}$ of surface elevation. The blue colors are for the ocean bathymetry below the floating ice shelves and the open ocean 

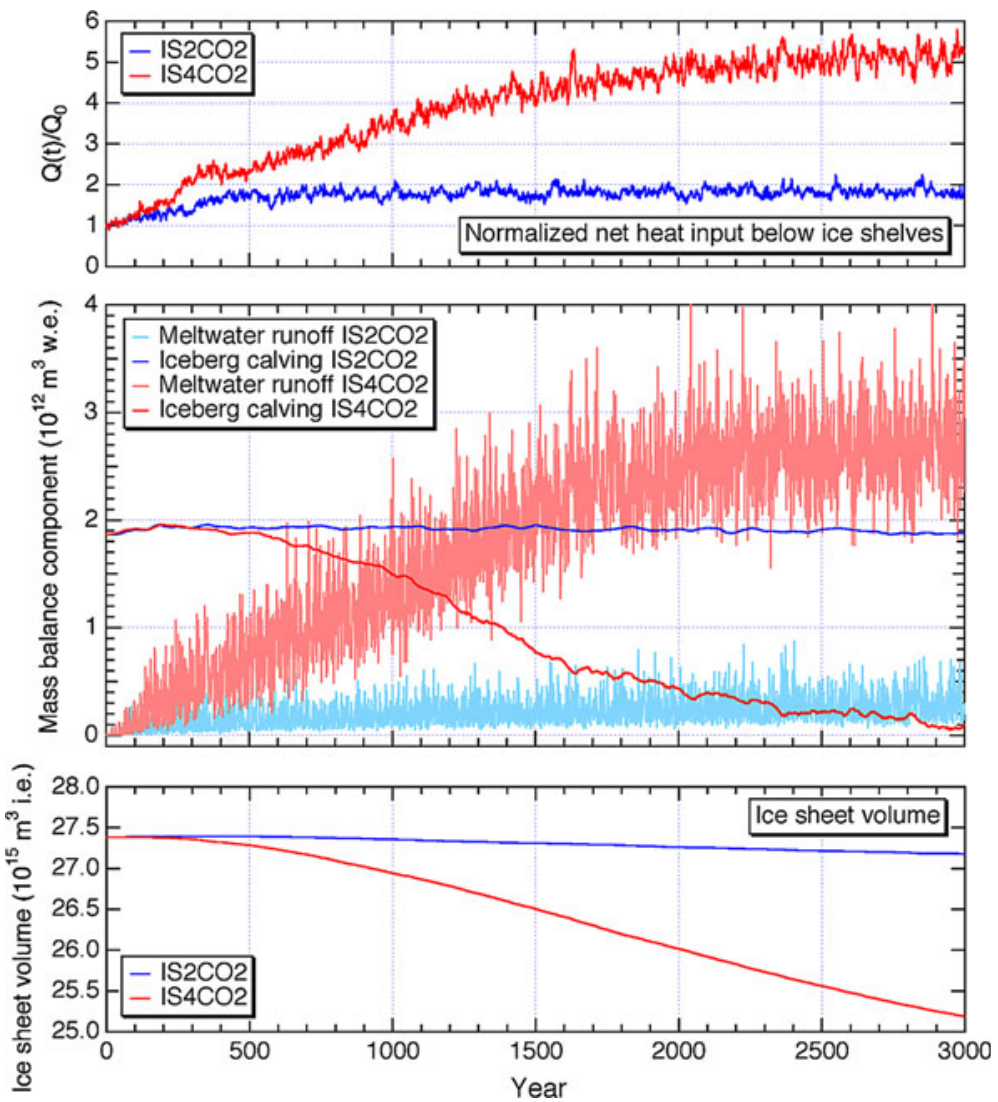

Fig. 9 Response of the Antarctic ice sheet to scenario IS2CO2 (blue lines) compared to scenario IS4CO2 (red lines) during 3,000 years. Shown are changes in ice sheet volume and general mass balance characteristics

significant thinning for elevations below $3,000 \mathrm{~m}$ can be detected from visual inspection of the surface contours.

The temperature increase over Antarctica in experiment IS2CO2 is generally not high enough to have a strong impact on the mass balance components of the Antarctic ice sheet (Fig. 9). For a mean annual warming gradually increasing to $4^{\circ} \mathrm{C}$ (Fig. 3), surface runoff from the grounded ice sheet never exceeds $20 \%$ of the snow accumulation. Ultimately, the average basal melting below the ice shelves almost doubles but iceberg calving remains almost constant for the whole duration of the experiment. As a result, Antarctic grounded ice volume increases somewhat during the first 300 years and by the end of the simulation is not more than $1 \%$ lower than the pre-industrial value, as shown in Fig. 9 together with the evolution of the same model characteristics of experiment IS4CO2.

\subsection{Contribution to Global Sea-Level Change}

The contribution of both ice sheets to global sea-level change in both experiments is displayed in Fig. 10. The curves mirror the evolution of ice sheet volume for the Greenland ice sheet but deviate from the grounded ice sheet volume for the Antarctic ice sheet as 


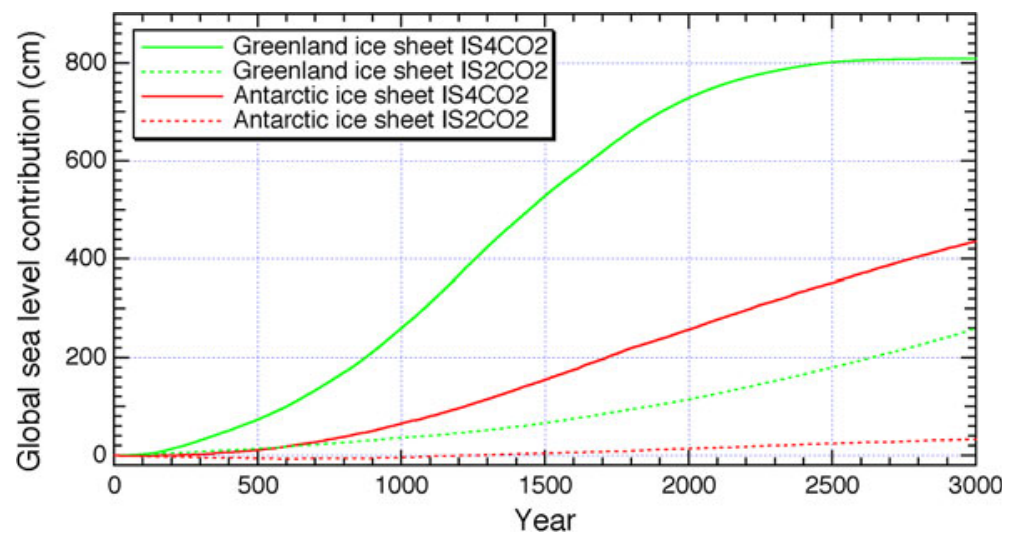

Fig. 10 Contributions to global sea level change from the Greenland (green) and Antarctic (red) ice sheet for scenarios IS4CO2 (solid lines) and IS2CO2 (dashed lines)

additional corrections have been made for isostatic depression and for ice displacing ocean water (Huybrechts 2002). The Greenland ice sheet always causes sea level to rise on account of the fast increase in surface runoff in a warmer climate. After 1,000 years, the ice sheet has lost ice volume equivalent to $35 \mathrm{~cm}$ in the low scenario IS2CO2 and more than $250 \mathrm{~cm}$ in the high scenario IS4CO2. In the low scenario, the Antarctic ice sheet actually lowers global sea level for the first 1,200 years with a maximum of $8 \mathrm{~cm}$ after 600 years. After 3,000 years in the high scenario, the Antarctic contribution is $\sim 400 \mathrm{~cm}$, or about half of the Greenland ice sheet contribution of $\sim 8 \mathrm{~m}$ possible in our model. The more or less steady rate of $2 \mathrm{~mm} \mathrm{year}^{-1}$ of sea level rise during the last 1,000 years of experiment IS4CO2 can be considered to bracket a maximum rate for a local warming of $10^{\circ} \mathrm{C}$. It also indicates that the Antarctic ice sheet is still far from equilibrium with the imposed climate change. In effect, very long time scales of the order of $10^{4}$ years are required before the Antarctic ice sheet eventually reaches a new steady state with less ice. Were the Antarctic ice sheet to continue to lose ice at this rate, its total melting would take $\sim 30,000$ years more to complete.

In both scenarios, the combined contribution of both ice sheets to sea-level change is always positive, except for the first 200 years of experiment IS2CO2 when the negative contribution of the Antarctic ice sheet almost exactly counteracts the positive contribution from the Greenland ice sheet. That corroborates earlier results obtained with the same set of ice-sheet models.

\section{Conclusion}

LOVECLIM is a useful tool to study long-term ice-sheet and climate changes. Even when keeping in mind the rather coarse resolution of the atmosphere and ocean components, high-latitude climate changes are found to be similar to those obtained with more comprehensive AOGCMs, indicating that the climatic component of LOVECLIM is sufficiently detailed for the current application. Consequently, typical rates of ice-sheet and sea-level changes compare well with those found in earlier studies with more detailed climatic components or in offline experiments with the ice sheet model for similar prescribed temperature and precipitation changes. 
An important conclusion is the long time scales associated with ice-sheet decay, partly caused by mitigating ice-climate interactions, and partly by the inertia of the ocean to the imposed greenhouse gas forcing, especially around Antarctica. On the millennial time scale, the results stress the dominant role of melting of the Greenland ice sheet at a rate in excess of $50 \mathrm{~cm}$ of sea level rise per century for a mean annual warming approaching $10^{\circ} \mathrm{C}$. In the model, the ice loss is almost entirely due to increased surface runoff. An often mentioned accelerated ice dynamic process such as surface melt induced basal lubrication is not included in the model, but this mechanism is increasingly considered unlikely as an important process to speed up ice flow (van de Wal et al. 2008; Sundal et al. 2011). Another potential candidate for generating accelerated ice flow arises from increased melting at calving fronts of tidewater glaciers linked to penetration of warm ocean water. However, the effectiveness of this process is limited in time as the Greenland ice sheet is found to become almost entirely land-based after a few centuries of sustained warming.

The results for Antarctica provide a remarkable contrast. For a regional warming below $3-4^{\circ} \mathrm{C}$, corresponding to a doubling of the $\mathrm{CO}_{2}$ concentration in LOVECLIM, increased accumulation is projected to dominate the mass balance, leading to a slight growth of the ice sheet. Processes causing significant ice volume loss, such as increased basal melting of the ice shelves, grounding-line retreat, and surface runoff, only become significant for greenhouse gas concentrations more than twice the pre-industrial value, and moreover take several centuries to become fully effective. The experiments discussed here limit the maximum rate of the Antarctic ice sheet contribution to global sea level rise to about $20 \mathrm{~cm}$ per century for a $4 \times \mathrm{CO}_{2}$ scenario corresponding to a regional warming of about $10^{\circ} \mathrm{C}$. The long-term response could however be larger in case sub-ice shelf melting would be concentrated near grounding lines, the large West Antarctic ice shelves were to break up, and calving fronts would develop in deep waters, but such behavior cannot be investigated with the current model set up.

Acknowledgments This study was carried out in the framework of successive projects funded by the Belgian Federal Science Policy Office within its Research Program on Science for a Sustainable Development under contracts EV/03/9B (MILMO) and SD/CS/01A (ASTER).

Open Access This article is distributed under the terms of the Creative Commons Attribution Noncommercial License which permits any noncommercial use, distribution, and reproduction in any medium, provided the original author(s) and source are credited.

\section{References}

Beckmann A, Goosse H (2003) A parameterization of ice shelf-ocean interaction for climate models. Ocean Mod 5(2):157-170. doi:10.1016/S1463-5003(02)00019-7

Bougamont M, Bamber JL, Ridley JK, Gladstone RM, Greuell W, Hanna E, Payne AJ, Rutt I (2007) Impact of model physics on estimating the surface mass balance of the Greenland ice sheet. Geophys Res Lett 34(17):5. doi:10.1029/2007g1030700

Brovkin V, Ganopolski A, Svirezhev Y (1997) A continuous climate-vegetation classification for use in climate-biosphere studies. Ecol Model 101(2-3):251-261. doi:10.1016/S0304-3800(97)00049-5

Charbit S, Paillard D, Ramstein G (2008) Amount of $\mathrm{CO}_{2}$ emissions irreversibly leading to the total melting of Greenland. Geophys Res Lett 35(12):L12503. doi:10.1029/2008GL033472

Driesschaert E, Fichefet T, Goosse H, Huybrechts P, Janssens I, Mouchet A, Munhoven G, Brovkin V, Weber S (2007) Modeling the influence of Greenland ice sheet melting on the Atlantic meridional overturning circulation during the next millennia. Geophys Res Lett 34(10):10707. doi:10.1029/ 2007GL029516

Fichefet T, Maqueda MAM (1997) Sensitivity of a global sea ice model to the treatment of ice thermodynamics and dynamics. J Geophys Res 102(C6):12609-12646. doi:10.1029/97JC00480 
Fichefet T, Poncin C, Goosse H, Huybrechts P, Janssens I, Le Treut H (2003) Implications of changes in freshwater flux from the Greenland ice sheet for the climate of the 21st century. Geophys Res Lett 30(17):1911. doi:1910.1029/2003GL017826

Goelzer H, Huybrechts P, Loutre MF, Goosse H, Fichefet T, Mouchet A (2010) Impact of Greenland and Antarctic ice sheet interactions on climate sensitivity. Clim Dyn online first. doi:10.1007/s00382010-0885-0

Goosse H, Fichefet T (1999) Importance of ice-ocean interactions for the global ocean circulation: a model study. J Geophys Res 104(C10):23337-23355. doi:10.1029/1999JC900215

Goosse H, Deleersnijder E, Fichefet T, England MH (1999) Sensitivity of a global coupled ocean-sea ice model to the parameterization of vertical mixing. J Geophys Res 104(C6):13681-13695. doi: 10.1029/1999JC900099

Goosse H, Brovkin V, Fichefet T, Haarsma R, Huybrechts P, Jongma J, Mouchet A, Selten F, Barriat PY, Campin JM, Deleersnijder E, Driesschaert E, Goelzer H, Janssens I, Loutre MF, Morales Maqueda M, Opsteegh T, Mathieu PP, Munhoven G, Pettersson E, Renssen H, Roche D, Schaeffer M, Tartinville B, Timmermann A, Weber S (2010) Description of the Earth system model of intermediate complexity LOVECLIM version 1.2 Geosci Model Dev 3:603-633. doi:10.5194/gmd-3-603-2010

Gregory J, Huybrechts P (2006) Ice-sheet contributions to future sea-level change. Phil Trans R Soc A 364(1844):1709-1731. doi:10.1098/rsta.2006.1796

Gregory JM, Huybrechts P, Raper SCB (2004) Threatened loss of the Greenland ice sheet. Nature 428:616. doi:10.1038/428616a

Hu AX, Meeh GA, Han WQ, Yin JJ (2009) Transient response of the MOC and climate to potential melting of the Greenland ice sheet in the 21st century. Geophys Res Lett 36:6. doi:10.1029/2009g1037998

Huybrechts P (2002) Sea-level changes at the LGM from ice-dynamic reconstructions of the Greenland and Antarctic ice sheets during the glacial cycles. Quat Sci Rev 21(1-3):203-231. doi:10.1016/S02773791(01)00082-8

Huybrechts P, de Wolde J (1999) The dynamic response of the Greenland and Antarctic ice sheets to multiple-century climatic warming. J Clim 12(8):2169-2188. doi:10.1175/1520-0442(1999)012<2169: TDROTG $>2.0 . \mathrm{CO} ; 2$

Huybrechts P, Miller H (2005) Flow and balance of the polar ice sheets. In: Hantel M (ed) Observed global climate. Landolt-Börnstein/New Series (Numerical data and functional relationships in science and technology), V/6 edn. Springer Verlag, Berlin, pp 13/1-13

Huybrechts P, Gregory J, Janssens I, Wild M (2004) Modelling Antarctic and Greenland volume changes during the 20th and 21st centuries forced by GCM time slice integrations. Global Planet Change 42(1-4):83-105. doi:10.1016/j.gloplacha.2003.11.011

Janssens I, Huybrechts P (2000) The treatment of meltwater retention in mass-balance parameterizations of the Greenland ice sheet. Ann Glaciol 31:133-140

Jungclaus JH, Haak H, Esch M, Roeckner E, Marotzke J (2006) Will Greenland melting halt the thermohaline circulation? Geophys Res Lett 33:L17708. doi:17710.11029/12006GL026815

Lunt D, de Noblet-Ducoudré N, Charbit S (2004) Effects of a melted Greenland ice sheet on climate, vegetation, and the cryosphere. Clim Dyn 23(7):679-694. doi:10.1007/s00382-004-0463-4

Meehl GA, Stocker TF, Collins WD, Friedlingstein P, Gaye AT, Gregory JM, Kitoh A, Knutti R, Murphy JM, Noda A, Raper SCB, Watterson IG, Weaver AJ, Zhao ZC (2007) Global climate projections. In: Qin D, Manning M, Chen Z et al (eds) Climate change 2007: the physical science basis Contribution of working group I to the fourth assessment report of the intergovernmental panel on climate change. Cambridge University Press, Cambridge, United Kingdom and New York, NY, USA

Mikolajewicz U, Groeger M, Maier-Reimer E, Schurgers G, Vizcaíno M, Winguth AME (2007a) Long-term effects of anthropogenic $\mathrm{CO}_{2}$ emissions simulated with a complex Earth system model. Clim Dyn 28(6):599-631. doi:10.1007/s00382-006-0204-y

Mikolajewicz U, Vizcaíno M, Jungclaus J, Schurgers G (2007b) Effect of ice sheet interactions in anthropogenic climate change simulations. Geophys Res Lett 34(18):5. doi:10.1029/2007g1031173

Mouchet A, François LM (1997) Sensitivity of a global oceanic carbon cycle model to the circulation and to the fate of organic matter: preliminary results. Phys Chem Earth 21(5-6):511-516. doi:10.1016/s00791946(97)81150-0

Oerlemans J (1991) The mass balance of the Greenland ice sheet: sensitivity to climate change as revealed by energy-balance modelling. Holocene 1(1):40-49. doi:10.1177/095968369100100106

Opsteegh JD, Haarsma RJ, Selten FM, Kattenberg A (1998) ECBilt: a dynamic alternative to mixed boundary conditions in ocean models. Tellus 50(3):348-367. doi:10.1034/j.1600-0870.1998.t011-00007.x

Ridley J, Huybrechts P, Gregory J, Lowe J (2005) Elimination of the Greenland ice sheet in a high $\mathrm{CO}_{2}$ climate. J Clim 18:3409-3427. doi:10.1175/JCLI3482.1 
Ridley J, Gregory JM, Huybrechts P, Lowe J (2010) Thresholds for irreversible decline of the Greenland ice sheet. Clim Dyn 35(6):1065-1073. doi:10.1007/s00382-009-0646-0

Rignot E, Kanagaratnam P (2006) Changes in the velocity structure of the Greenland ice sheet. Science 311(5763):986-990. doi:10.1126/Science.1121381

Rignot E, Bamber JL, Van Den Broeke MR, Davis C, Li Y, Van De Berg WJ, Van Meijgaard E (2008a) Recent Antarctic ice mass loss from radar interferometry and regional climate modelling. Nat Geosci 1(2):106-110. doi:10.1038/ngeo102

Rignot E, Box J, Burgess E, Hanna E (2008b) Mass balance of the Greenland ice sheet from 1958 to 2007. Geophys Res Lett 35:L20502. doi:10.1029/2008GL035417

Solomon S, Qin D, Manning M, Chen Z, Marquis M, Averyt K, Tignor M, Miller H (eds) (2007) Contribution of Working Group I to the Fourth Assessment Report of the Intergovernmental Panel on Climate Change, 2007. Cambridge University Press, Cambridge. United Kingdom and New York, NY, USA

Stone E, Lunt D, Rutt I, Hanna E (2010) Investigating the sensitivity of numerical model simulations of the modern state of the Greenland ice-sheet and its future response to climate change. Cryosphere 4(3):397-417. doi:10.5194/tc-4-397-2010

Sundal AV, Shepherd A, Nienow P, Hanna E, Palmer S, Huybrechts P (2011) Melt induced speed-up of Greenland ice sheet offset by efficient subglacial drainage. Nature 469:521-524. doi:10.1038/ nature09740

Swingedouw D, Fichefet T, Huybrechts P, Goosse H, Driesschaert E, Loutre M-F (2008) Antarctic ice-sheet melting provides negative feedbacks on future climate warming. Geophys Res Lett 35((17)):L17705. doi:10.1029/2008GL034410

Van de Wal RSW, Boot W, van den Broeke MR, Smeets CJPP, Reijmer CH, Donker JJA, Oerlemans J (2008) Large and rapid melt-induced velocity changes in the ablation zone of the Greenland ice sheet. Science 321:111-113. doi:10.1126/science.1158540

Van Den Broeke M, Bamber J, Ettema J, Rignot E, Schrama E, Van De Berg WJ, Van Meijgaard E, Velicogna I, Wouters B (2009) Partitioning recent Greenland mass loss. Science 326(5955):984-986. doi: $10.1126 /$ science. 1178176

Vizcaíno M, Mikolajewicz U, Groeger M, Maier-Reimer E, Schurgers G, Winguth AME (2008) Long-term ice sheet-climate interactions under anthropogenic greenhouse forcing simulated with a complex Earth system model. Clim Dyn 31(6):665-690. doi:10.1007/s00382-008-0369-7

Vizcaíno M, Mikolajewicz U, Jungclaus J, Schurgers G (2010) Climate modification by future ice sheet changes and consequences for ice sheet mass balance. Clim Dyn 34(2-3):301-324. doi: 10.1007/s00382-009-0591-y 